\title{
Adrenocortical function in patients with macrometastases of the adrenal gland
}

\author{
Amelie Lutz, Marija Stojkovic ${ }^{1}$, Michael Schmidt ${ }^{1}$, Wiebke Arlt $^{1}$, Bruno Allolio ${ }^{1}$ and Martin Reincke \\ Department of Internal Medicine, University of Freiburg, Freiburg, Germany and ${ }^{1}$ Department of Internal Medicine, University of Würzburg, \\ Würzburg, Germany
}

(Correspondence should be addressed to M Reincke, Schwerpunkt Endokrinologie, Abteilung Innere Medizin II, Universitätsklinik Freiburg, Hugstetterstraße 55, D-79106 Freiburg, Germany; Email: reincke@mm21.ukl.uni-freiburg.de)

\begin{abstract}
Objective: Metastases of the adrenal gland are a frequent finding in patients with malignant tumors like bronchogenic carcinoma or breast cancer. Only limited and conflicting data on adrenocortical function in these patients are available.

Design: Cross-sectional study.

Methods: We investigated the impact of adrenal macrometastases on adrenocortical function in a series of 28 tumor patients using the $\mathrm{ACTH}_{1-24}$ stimulation test and dexamethasone suppression test. Seven normal controls (Con), eleven patients without adrenal metastases (No Met), eight patients with unilateral (Uni Met) and nine patients with bilateral adrenal metastases (Bil Met) were investigated. Results: The prevalence of adrenal insufficiency was low in our study population, with only two of nine patients with bilateral metastases having subclinical adrenocortical insufficiency. In the remaining patients with uni- or bilateral metastases, baseline and stimulated cortisol concentrations were higher than in controls and cancer patients without metastases (baseline cortisol (in nmol/l): Con: $307 \pm 33.2$ vs Uni Met: $440 \pm 53.5$, and Bil Met: $637.6 \pm 92.1, P=0.04$ by ANOVA; cortisol $60 \mathrm{~min}$ after ACTH $_{1-24}$ : Con: $794.6 \pm 41.2$ vs Uni Met: $990.8 \pm 92.9$, and Bil Met: $1151.4 \pm 155.5, P=0.03$ by ANOVA). Simultaneously, baseline and stimulated serum aldosterone concentrations were significantly blunted in the tumor groups.

Conclusions: Adrenal insufficiency is infrequent and develops only in patients with bilateral metastases. However, the majority of patients have activation of the hypothalamic-pituitary-adrenal axis despite adrenal metastases with strongly elevated cortisol concentrations.
\end{abstract}

European Journal of Endocrinology 143 91-97

\section{Introduction}

Metastases of the adrenal gland are a frequent finding in patients with advanced solid tumors (1-4). In autopsy series, the prevalence of adrenal metastases was $36-$ $44 \%$ in bronchiogenic carcinoma $(4,5), 20-58 \%$ in breast cancer $(2,4,5), 50-60 \%$ in malignant melanoma $(4,6), 11-21 \%$ in gastric cancer $(2,4,7)$ and $4.8-14 \%$ in colorectal cancer $(4,8)$. In most of these patients, the metastases remained clinically silent and did not require specific therapy.

Adrenocortical insufficiency is a rare but potentially lethal disease. Autoimmune adrenalitis is the most frequent cause accounting for $70 \%$ of the cases, followed by adrenal tuberculosis $(15 \%)(9,10)$. Also, adrenal macrometastases are a well-recognized but infrequent cause of adrenal insufficiency (11-16), and were already reported in the original publication of Addison (17). In two larger series, Cedemark \& Sjoberg (18) and
Redman et al. (19) reported diverging results concerning the prevalence of adrenocortical insufficiency in patients with adrenal metastases. Both studies reported limited hormonal data and were hampered by the lack of an appropriate control group. This is especially necessary since cancer patients may have an activated hypothalamic-pituitary-adrenal axis, due to increased physiological stress (20) and interactions between the tumor, the immune and the endocrine system (21). In this study, we evaluated the adrenocortical responsiveness to exogenous adrenocorticotropin (ACTH) in a series of seven normal controls, eleven patients without adrenal metastases, eight patients with unilateral and nine patients with bilateral macrometastases. Our data showed that adrenal insufficiency is only found in patients with large $(>4 \mathrm{~cm})$ bilateral adrenal metastases. In addition, we have demonstrated that cancer patients generally show activation of the hypothalamic-pituitary axis which is more pronounced in the advanced stage. 
Table 1 Clinical data of normal control subjects, tumor patients without metastases, and with unilateral and bilateral metastases. Values are means \pm S.E.M.

\begin{tabular}{|c|c|c|c|c|}
\hline & Sex & $\begin{array}{c}\text { Age } \\
\text { (years) }\end{array}$ & Diagnosis & $\begin{array}{c}\text { Adrenal } \\
\text { metastases } \\
(\text { Maximum size }(\mathrm{cm}))\end{array}$ \\
\hline Control subjects $(n=7)$ & $\begin{array}{l}5 \mathrm{~F} \\
2 \mathrm{M}\end{array}$ & $35 \pm 4$ & - & - \\
\hline $\begin{array}{l}\text { Patients without adrenal metastases }(n=11) \text {, } \\
45.5 \% \text { with distant metastases }\end{array}$ & $\begin{array}{l}3 \mathrm{~F} \\
8 \mathrm{M}\end{array}$ & $66 \pm 2$ & $\begin{array}{l}\text { Bronchiogenic carcinoma } \\
\text { Oat cell carc. }(n=3) \\
\text { Adenocarcinoma }(n=2) \\
\text { Squamous cell carc. }(n=6)\end{array}$ & - \\
\hline $\begin{array}{l}\text { Patients with unilateral metastases }(n=8) \text {, } \\
62.5 \% \text { with distant metastases }\end{array}$ & $\begin{array}{l}3 \mathrm{~F} \\
5 \mathrm{M}\end{array}$ & $60 \pm 5$ & $\begin{array}{l}\text { Bronchiogenic carcinoma } \\
\text { Oat cell carc. }(n=4) \\
\text { Adenocarcinoma }(n=2) \\
\text { Squamous cell carc. }(n=2)\end{array}$ & $\begin{array}{l}1.9 \pm 0.2 \\
(1.1-6.0)\end{array}$ \\
\hline $\begin{array}{l}\text { Patients with bilateral metastases }(n=9) \text {, } \\
77.7 \% \text { with distant metastases }\end{array}$ & $\begin{array}{l}5 \mathrm{~F} \\
4 \mathrm{M}\end{array}$ & $67 \pm 3$ & $\begin{array}{l}\text { Bronchiogenic carcinoma } \\
\text { Oat cell carc. }(n=1) \\
\text { Adenocarcinoma }(n=3) \\
\text { Squamous cell carc. }(n=1) \\
\text { Breast carcinoma }(n=1) \\
\text { Prostate cancer }(n=1) \\
\text { Hypopharynx carc. }(n=1) \\
\text { Melanoma }(n=1)\end{array}$ & $\begin{array}{l}4.5 \pm 1.0 \\
(1.0-12.0)\end{array}$ \\
\hline
\end{tabular}

F, female; $M$, male; carc., carcinoma.

\section{Patients and methods}

\section{Patients}

Seven normal controls, eleven tumor patients without adrenal metastases $(45.5 \%$ with other distant metastases), eight tumor patients with unilateral adrenal metastases $(62.5 \%$ with other distant metastases) and nine tumor patients with bilateral metastases (77.7\% with other distant metastases) were studied in a prospective fashion (for clinical data see Table 1). The 17 patients with uni- or bilateral metastases were recruited from a total of 34 patients with this condition treated at our institution during a 2 -year period. The remaining 17 patients were excluded for the reasons listed below. Exclusion criteria were: disorders of the hypothalamic-pituitary-adrenal axis, glucocorticoid therapy, renal insufficiency (creatinine $>2.0 \mathrm{mg} / \mathrm{dl}$ ), liver insufficiency, or sepsis/infection. Also, patients with ectopic ACTH syndrome were excluded. All patients and control subjects gave their written informed consent. The study protocol was approved by the ethical committee of the University Hospital of Würzburg.

The patients were carefully evaluated for signs and symptoms of adrenal insufficiency. All patients underwent routine computed tomography of the abdomen with administration of oral and i.v. contrast material as part of the staging procedures. Adrenal metastases were diagnosed if a significant adrenal mass was present $(>1 \mathrm{~cm})$, which showed at least two of the following criteria: irregular boundaries, irregular contrast enhancement, increase in size during follow-up or regression after systemic chemotherapy $(22,23)$.

\section{$\boldsymbol{A C T H}_{1-24}$ stimulation test}

At $0900 \mathrm{~h}$ all subjects underwent an ACTH stimulation test using $250 \mu \mathrm{g} \mathrm{ACTH}_{1-24}$ (Synacthen; Ciba-Geigy, Wehr am Rhein, Germany). An indwelling canula was inserted in an antecubital vein at $-60 \mathrm{~min}$, and the subjects were seated in an upright position throughout the test. At -30 and 0 min, blood was drawn for baseline determination of plasma ACTH, plasma renin activity, serum cortisol and serum aldosterone. After bolus injection of $\mathrm{ACTH}_{1-24}$, blood was drawn at 30, 60 and $90 \mathrm{~min}$ for determination of serum cortisol and aldosterone.

\section{Diagnostic criteria for adrenal insufficiency}

Overt adrenal insufficiency was defined by standard criteria as a serum cortisol response to stimulation with $\mathrm{ACTH}_{1-24}$ below $560 \mathrm{nmol} / \mathrm{l} \quad(<20 \mu \mathrm{g} / \mathrm{dl}) \quad(9,10)$. Subclinical adrenal insufficiency was defined as an elevated ACTH:cortisol ( $\mathrm{pmol} / \mathrm{l}: \mathrm{nmol} / \mathrm{l}$ ) ratio $>0.028$ (24) and a missing response to stimulation with $\mathrm{ACTH}_{1-24}$ (increase below $90 \mathrm{nmol} / \mathrm{l}(<3 \mu \mathrm{g} / \mathrm{dl})$ ), but normal baseline or maximum stimulated cortisol concentrations above $560 \mathrm{nmol} / \mathrm{l}$.

\section{Dexamethasone suppression test}

In a subgroup of six normal subjects and twelve patients, suppressibility of plasma ACTH and serum cortisol by dexamethasone was determined. The remaining sixteen patients could not be studied for the following reasons: initiation of chemotherapy, withdrawn consent, and deterioration of clinical status. The 
subjects received $3 \mathrm{mg}$ dexamethasone orally at $2300 \mathrm{~h}$, and plasma ACTH and serum cortisol levels were determined at $0800 \mathrm{~h}$ the following morning. The dose of $3 \mathrm{mg}$ instead of $2 \mathrm{mg}$ was used to reduce the number of false positive test results which may be seen in cancer in-patient cohorts. The $3 \mathrm{mg}$ dexamethasone suppression test has been evaluated in our institution previously (25).

\section{Assays}

All hormones were determined with commercially available assays. Plasma ACTH was measured by an immunoluminometric assay (LUMItest; Brahms Diagnostica, Berlin, Germany), the plasma renin activity by RIA (Sorin), serum cortisol and serum aldosterone by RIA (DPC; Biermann GmbH, Bad Nauheim, Germany). The intra- and interassay variability was below $10 \%$ for all assays.

\section{Statistics}

After exclusion of patients with adrenal insufficiency $(n=2)$ the values of each patient group are expressed as means \pm S.E.M. Significance of differences between groups were determined by ANOVA with correction for multiple comparisons using a PowerMacintosh computer and the StatView 4.5 program. $P<0.05$ was considered statistically significant.

\section{Results}

\section{Prevalence of adrenocortical insufficiency in patients with adrenal metastases}

Symptoms suggestive of adrenocortical insufficiency were present in a substantial percentage of patients with and without adrenal metastases (Table 2). In contrast, the prevalence of adrenal insufficiency using biochemical criteria in these patients was low. None of the

Table 2 Signs and symptoms possibly due to adrenocortical insufficiency in tumor patients without adrenal metastases, and with unilateral and bilateral adrenal metastases.

\begin{tabular}{lccc}
\hline & \multicolumn{3}{c}{ Patients with: } \\
\cline { 2 - 4 } & $\begin{array}{c}\text { No } \\
\text { metastases } \\
(n=11)\end{array}$ & $\begin{array}{c}\text { Unilateral } \\
\text { metastases } \\
(n=8)\end{array}$ & $\begin{array}{c}\text { Bilateral } \\
\text { metastases } \\
(n=9)\end{array}$ \\
\hline Weakness/adynamia & $3(27 \%)$ & $6(75 \%)$ & $5(56 \%)$ \\
Fatigue & $1(9 \%)$ & $2(25 \%)$ & $2(22 \%)$ \\
Anorexia & $3(27 \%)$ & $5(63 \%)$ & $6(67 \%)$ \\
Nausea/vomiting & $2(18 \%)$ & $3(38 \%)$ & $2(22 \%)$ \\
Weight loss & $1(9 \%)$ & $4(50 \%)$ & $5(56 \%)$ \\
Hypotension & $1(9 \%)$ & 0 & $3(33 \%)$ \\
Electrolyte disturbances & 0 & 0 & $1(11 \%)$ \\
Hyperpigmentation & 0 & 0 & 0 \\
\hline
\end{tabular}

patients had evidence of overt adrenocortical insufficiency. However, two of nine patients with large bilateral metastases had elevated ACTH:cortisol ratios and did not respond to stimulation with $\mathrm{ACTH}_{1-24}$ (Fig. 1 and Table 3), suggesting mild impairment of adrencortical function (subclinical adrenal insufficiency). Both patients received glucocorticoid replacement therapy, without clinical improvement. They were excluded from further analyses.

\section{Cortisol and aldosterone response to $\mathrm{ACTH}_{1-24}$}

Compared with normal control subjects, tumor patients, especially with metastases, had higher baseline and stimulated cortisol concentrations (Fig. 2a). Simultaneously, serum aldosterone concentrations were lower in tumor patients compared with controls (Fig. 2b). Plasma renin activity (ng/ml per h) was higher in tumor patients, but the difference did not reach statistical significance (controls: $0.8 \pm 1.4$; patients without metastases: $1.6 \pm 0.7$; patients with unilateral metastases: $1.1 \pm 0.4$; patients with bilateral metastases: $1.1 \pm 0.4 ; P=$ not significant).

\section{Dexamethasone suppression test}

Six tumor patients without metastases, three patients with unilateral metastases and three patients with bilateral metastases underwent dexamethasone suppression testing with $3 \mathrm{mg}$ dexamethasone. Dexamethasone suppressed plasma ACTH concentrations both in controls and tumor patients. In contrast, serum cortisol concentrations (nmol/l) were incompletely suppressed in ten of twelve patients (controls: $30 \pm 5$, normal range $<55 \mathrm{nmol} /$ l; patients without metastases: $110 \pm 30$; patients with unilateral metastases: $100 \pm 40$; patients with bilateral metastases: $470 \pm 115$ ).

\section{Discussion}

Adrenal metastases are a very frequent finding in patients with bronchogenic carcinoma. In a retrospective study, Silvestri et al. (26) found adrenal metastases in 26 of 173 patients (15\%) using computed tomography, with a positive correlation between tumor stage and the prevalence of adrenal metastases. Salvatierra et al. (27) reported a prevalence of $7.5 \%$ in 146 patients with potentially resectable non-small cell carcinomas. However, studies using computed tomography may substantially underestimate the frequency of adrenal metastases. For example, Pagani (28) reported on 32 patients with normal adrenal morphology on computed tomography who underwent a fineneedle biopsy of the adrenal. Of these, four patients $(12 \%)$ were found to have micrometastases of the adrenal gland.

Compared with the prevalence of adrenal metastases, adrenocortical insufficiency in these patients seems to 


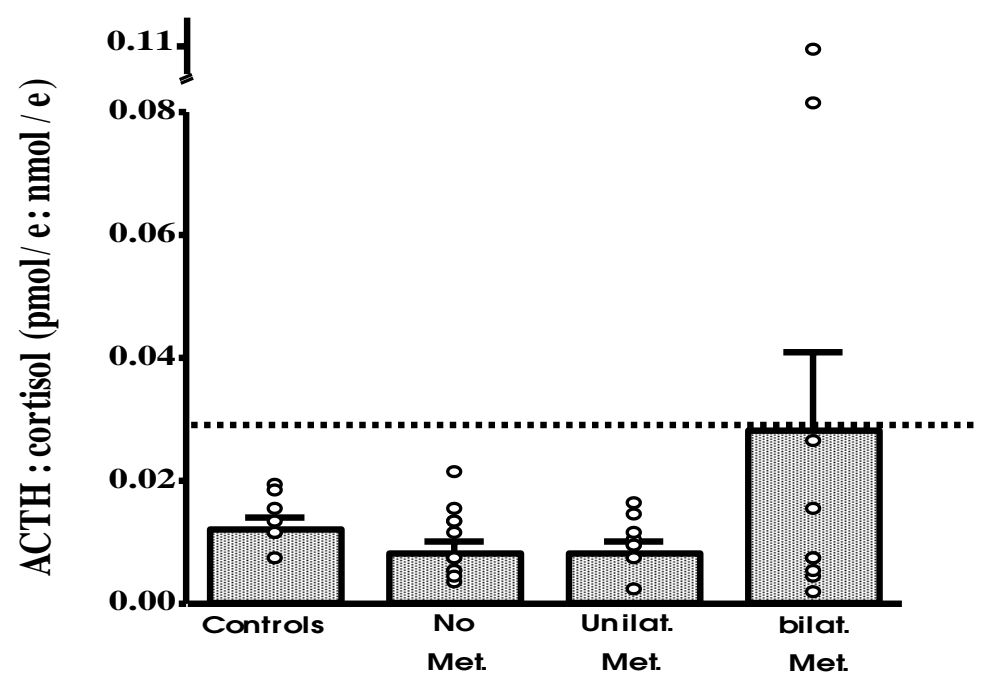

Figure 1 Ratio of plasma ACTH (pmol/l) to serum cortisol $(\mathrm{nmol} / \mathrm{l})$ in control subjects, patients without metastases (No Met.), patients with unilateral adrenal metastases (Unilat. Met.) and patients with bilateral adrenal metastases (bilat. Met.). Means \pm S.E.M. and the individual values for each subject (circles) are shown. The broken line represents the upper normal range of $0.028(21)$. be rare. Most data on patients with adrenal insufficiency due to adrenal metastases have been reported as case reports $(11-16,18-19,29,30)$, whereas a systematic, prospective evaluation of the prevalence of adrenal insufficiency is missing. In addition, the criteria used for the diagnosis of adrenal insufficiency are highly variable, ranging from clinical evidence only to nonstandardized biochemical criteria. Sheeler et al. (29) reported four patients with adrenal insufficiency caused by bilateral adrenal metastases, the diameter of these masses being at least $3 \mathrm{~cm}$. The diagnosis was based on a 48 -h ACTH infusion with plasma cortisol $<45 \mu \mathrm{g} / \mathrm{dl}$. In a retrospective study, Seidenwurm et al. (30) found four cases of adrenal insufficiency in 21 patients (19\%). All patients had bilateral involvement or only one remaining adrenal due to unilateral adrenalectomy. Only two of the cases with adrenal insufficiency underwent endocrine function tests to confirm the diagnosis. Cedemark \& Sjoberg (18) prospectively evaluated three patients with unilateral and four patients with bilateral adrenal metastases, three of whom had symptoms suggesting adrenal insufficiency. The size of the metastases was not given, but all patients had normal responses during the short ACTH stimulation test. Gamelin et al. (31) in a prospective study reported on 127 consecutive patients with nonHodgkin's lymphoma. Overall, adrenal involvement was found in eight patients $(6 \%)$, with four of five patients $(80 \%)$ with bilateral adrenal enlargement having adrenal insufficiency. The size of the metastases was not reported in this paper, and the biochemical criteria for diagnosing adrenal insufficiency was a less than twofold increase of serum cortisol over baseline. Redman et al. (19) studied prospectively 15 patients with bilateral adrenal metastases, with five patients having adrenal insufficiency (serum cortisol increase $<5 \mu \mathrm{g} / \mathrm{dl}$ after $\mathrm{ACTH}_{1-24}$ or stimulated serum cortisol $<15 \mu \mathrm{g} / \mathrm{dl})$. However, at least in two patients,

Table 3 Clinical and endocrine characteristics of patients with bilateral metastases. Baseline cortisol concentrations, maximum cortisol concentrations and the cortisol increase after stimulation with $\mathrm{ACTH}_{1-24}$ are shown.

\begin{tabular}{|c|c|c|c|c|c|c|}
\hline $\begin{array}{l}\text { Patient } \\
\text { no. }\end{array}$ & $\begin{array}{l}\text { Size of adrenal } \\
\text { metastases }(\mathrm{cm}) \\
(\text { right/left })\end{array}$ & $\begin{array}{c}\text { Baseline } \\
\text { cortisol } \\
(\mathrm{nmol} / \mathrm{l})\end{array}$ & $\begin{array}{c}\text { Maximum } \\
\text { cortisol } \\
(\mathrm{nmol} / \mathrm{l})\end{array}$ & $\begin{array}{c}\text { Cortisol } \\
\text { increase } \\
(\mathrm{nmol} / \mathrm{l})\end{array}$ & $\begin{array}{c}\text { Plasma } \\
\text { ACTH } \\
\text { (pmol/l) }\end{array}$ & $\begin{array}{l}\text { ACTH: } \\
\text { cortisol } \\
\text { ratio }\end{array}$ \\
\hline $1^{*}$ & $6 / 12$ & 577 & 657 & 80 & 45.9 & 0.08 \\
\hline $2^{*}$ & $4 / 10$ & 646 & 715 & 69 & 68.5 & 0.110 \\
\hline 3 & $6 / 1$ & 1239 & 1410 & 171 & 7.5 & 0.006 \\
\hline 4 & $3 / 5$ & 665 & 1536 & 871 & 2.8 & 0.004 \\
\hline 5 & $5 / 2$ & 331 & 1009 & 678 & 4.6 & 0.014 \\
\hline 6 & $1 / 5$ & 502 & 1217 & 715 & 1.5 & 0.003 \\
\hline 7 & $3 / 2.5$ & 524 & 1741 & 1217 & 13.5 & 0.026 \\
\hline 8 & $2 / 3$ & 872 & 2704 & 1832 & 0.4 & 0.0005 \\
\hline 9 & $1 / 1$ & 384 & 599 & 215 & 2.2 & 0.006 \\
\hline $\begin{array}{l}\text { Normal } \\
\text { range }\end{array}$ & & $140-700$ & $>560$ & & $<10$ & $<0.028$ \\
\hline
\end{tabular}

*Patients with subclinical adrenal insufficiency. 
(a)

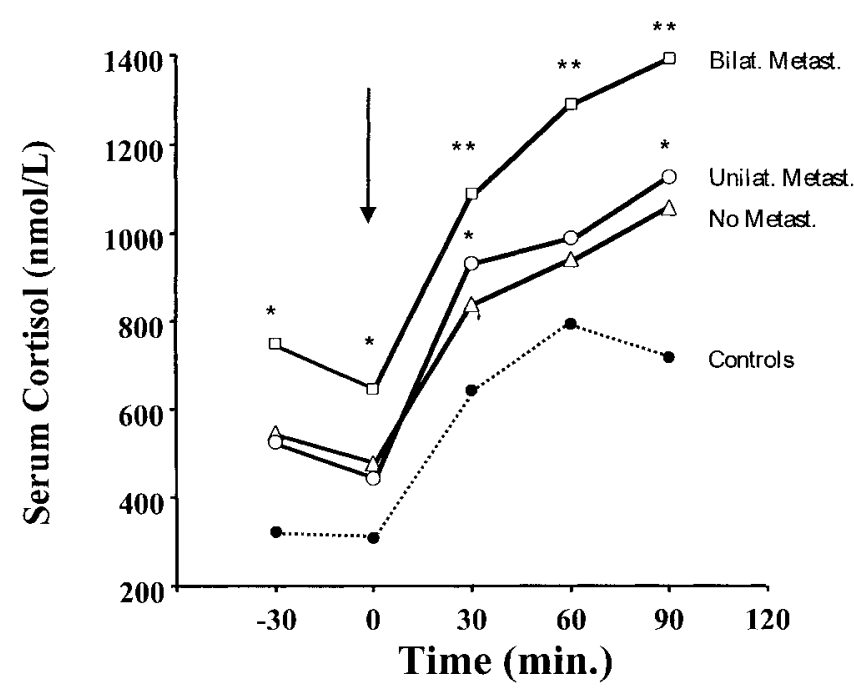

(b)

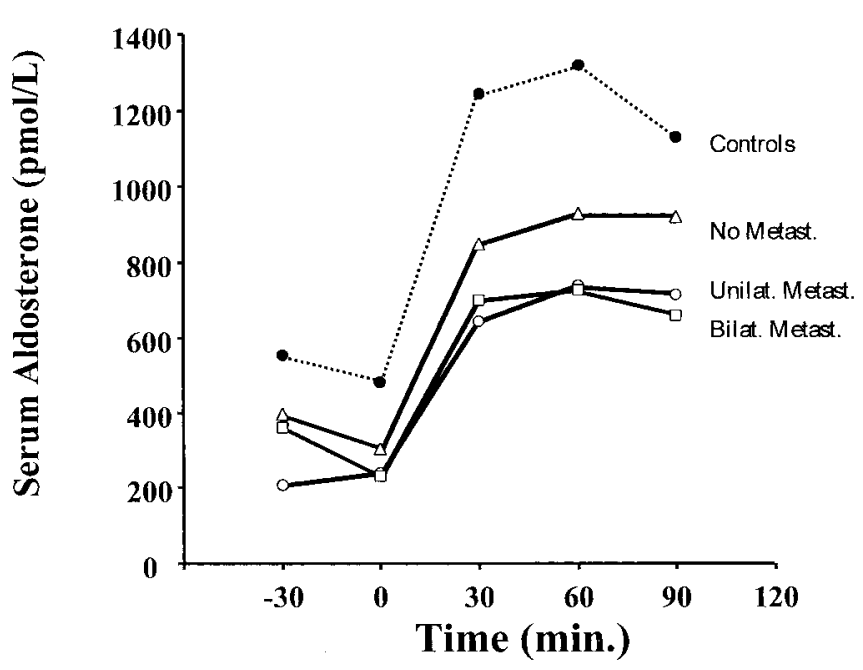

Figure 2 Mean hormone response to stimulation with $\mathrm{ACTH}_{1-24}$ in normal subjects and patients with and without adrenal metastases. (a) Mean serum cortisol concentrations (nmol/l \pm S.E.M.): controls at 0 min $307.4 \pm 33.2$; at $60 \mathrm{~min} 794.6 \pm 41.2$. Patients without adrenal metastases (No Metast.) at $0 \mathrm{~min}$ $477.5 \pm 64.9$; at $60 \mathrm{~min} 939.7 \pm 99.2$. Patients with unilateral adrenal metastases (Unilat. Metast.) at 0 min 440.4 \pm 53.5 ; at 60 min 990.8 \pm 92.9 . Patients with bilateral adrenal metastases (Bilat. Metast.) at $0 \mathrm{~min} 637.6 \pm 92.1$; at $60 \mathrm{~min} 1151.4 \pm 155.5$. (b) Mean serum aldosterone concentrations (pmol/l \pm S.E.M.): controls at 0 min $480 \pm 70$; at 60 min $1319 \pm 222$. Patients without adrenal metastases at $0 \mathrm{~min} 302 \pm 82$; at $60 \mathrm{~min} 931 \pm 188$. Patients with unilateral adrenal metastases at 0 min 237 \pm 43 ; at $60 \min 739 \pm 168$. Patients with bilateral adrenal metastases at $0 \min 315 \pm 130$; at $60 \min 721 \pm 151$. ${ }^{\star} P<0.05,{ }^{* \star} P<0.01$ vs control subjects. the diagnosis of adrenal insufficiency seems to be questionable, because baseline cortisol concentrations were already high, exceeding $25 \mu \mathrm{g} / \mathrm{dl}(700 \mathrm{nmol} / \mathrm{l})$ which suggests near-maximal endogenous stimulation of the adrenal cortex. Neither in this nor in the other articles mentioned above were plasma ACTH concentrations given although plasma ACTH is an important parameter if primary adrenal insufficiency is suspected (24). In summary, the prevalence of adrenal insufficiency in patients with adrenal metastases reported in the literature ranges from 0 to $80 \%$. These differences seem to be mainly due to the preselection of patients and variable criteria for the diagnosis of adrenal insufficiency.

We studied nine patients with bilateral adrenal metastases and compared the results with that of eleven tumor patients without metastases and eight tumor patients with unilateral metastases. These patients comprised all eligible patients with adrenal metastases during a 2-year period at our institution. In addition, we studied seven normal control subjects. Clinically, tumor patients frequently had signs and symptoms suggestive of adrenal insufficiency. Since no clear correlation between the clinical data and adrenocortical function testing was found, these symptoms are more likely due to the underlying malignancy than caused by a relative glucocorticoid deficit. Clinical assessment of adrenal insufficiency, therefore, is of little value in these patients, and the prevalence of adrenal impairment will be overestimated if the diagnosis of adrenal insufficiency is based on features like weakness, fatigue, anorexia, weight loss, and vomiting only.

Using standard criteria (serum cortisol $<560 \mathrm{nmol} / \mathrm{l}$ after $\mathrm{ACTH}_{1-24}$ stimulation $\left.(9,10)\right)$, none of our 
patients with adrenal metastases had overt adrenal insufficiency. Instead, patients with adrenal metastases had increased glucocorticoid concentrations as may be seen in patients with chronic stress. The cortisol excess was more pronounced in patients with bilateral than in patients with unilateral adrenal metastases. Stimulation of adrenocortical function in tumor patients may result from increased inflammatory cytokine secretion of immunocompetent cells in response to the tumor (32, 33) or by the tumor itself (34), such as tumor necrosis factor- $\alpha$ (35), interleukin-1 (36) and interleukin-6 (37) or by the increased physical and mental stress of tumor patients $(20,21,38)$. These data suggest that plasma ACTH and cortisol concentrations within the lower normal range of healthy subjects may not be sufficient in reflecting 'eucortisolism' in patients with advanced tumor stages. In these subjects, higher cortisol concentrations are required to maintain homeostasis. Therefore, diagnostic evaluation of patients with bilateral metastases and therapeutic recommendations for suspected adrenal insufficiency have to take into account the fact that the hypothalamic-pituitaryadrenal axis is activated in tumor patients.

Elevated plasma ACTH concentrations or an elevated ACTH:cortisol ratio are sensitive indicators of adrenal insufficiency $(10,24)$. Elevation of plasma ACTH characteristically precedes the onset of overt adrenal insufficiency (39). Using the ACTH:cortisol ratio, two of nine patients with bilateral adrenal metastases had mild impairment of adrenocortical function. We defined this type of dysfunction as subclinical adrenal insufficiency. Baseline cortisol concentrations were in the upper normal range in both patients, but the response to stimulation with ACTH was missing. Both patients had large metastases exceeding $4 \mathrm{~cm}$ on both sides. Glucocorticoid and mineralocorticoid treatment was started, but clinical improvement was missing, and both patients died within 2 months due to progressive disease. Our findings and data from the literature suggest that patients with bilateral adrenal metastases should be evaluated for the presence of adrenal insufficiency. Patients with large metastases are especially at risk for adrenal insufficiency and should receive careful follow-up even if baseline testing is normal. In our opinion, the ACTH:cortisol ratio may be superior to $\mathrm{ACTH}_{1-24}$ testing since interpretation of the results of the ACTH stimulation test is difficult due to the various degrees of stress to which tumor patients are exposed.

We found an increased cortisol response to ACTH stimulation concomitantly with a decreased aldosterone response. These data favor a shift in adrenal steroidogenesis from mineralocorticoid secretion towards glucocorticoid secretion, a characteristic feature found in patients with critical illness (40-42). These data have led to the conclusion that the function of the zona glomerulosa and reticularis is impaired in critical illness. We found similar changes in steroid hormone profiles in this study suggesting impairment of zona glomerulosa function in tumor patients. The degree of dysfunction was more severe in patients with adrenal metastases than in patients without adrenal metastases. This may be explained by the advanced tumor stages of the former patients associated with increased physical stress. However, a stimulatory paracrine effect of adrenal metastases on glucocorticoid secretion in these patients cannot be excluded. Whether this is mediated at the level of the hypothalamic pituitary unit by increased ACTH release, by direct stimulation of the adrenal cortex via inflammatory cytokines (37) or by humoral factors produced by the adrenal metastases (e.g. pro-opiomelanocortin peptides, cytokines, other neuroendocrine peptides) has to be determined. The results of the dexamethasone suppression test are in favor of the latter possibility. Plasma ACTH concentrations were readily suppressible in these patients in response to dexamethasone, whereas cortisol secretion was partially resistant. The discrepancy between plasma ACTH and cortisol response to dexamethasone was especially evident in patients with bilateral adrenal metastases, supporting the concept that glucocorticoid secretion may be influenced by locally produced factors in adrenal metastases which may act as paracrine (and partially ACTH-independent) stimuli for cortisol synthesis. Whether this hypothesis turns out to be true has to be proven in a larger cohort of patients with adrenal metastases.

\section{Acknowledgements}

M R was supported by a grant from the Wilhelm-Sander Stiftung, München.

\section{References}

1 Willis RA. Secondary tumors of the adrenals. In The Spread of Tumors in the Human Body, edn 2, pp 199. London: Butterworth \& Co. Ltd, 1952.

2 Abrams HL, Spiro R \& Goldstein N. Metastases in carcinoma. Cancer 19503 74-84.

3 Bullock WK \& Hirst AE. Metastatic carcinoma of the adrenal. American Journal of the Medical Sciences 1953226 521-530.

4 Glomset DA. The incidence of metastases of malignant tumors to the adrenals. American Journal of Cancer 193832 57-61.

5 Willis RA. In Pathology of Tumors, pp 178-180. Ed. CV Mosby. St Louis, 1957.

6 Gupta DT \& Brasfield R. Metastatic melanoma. Cancer 196417 1323-1339.

7 Cedermark BJ, Blumenson LE, Pickren JW \& Elias EG. The significance of metastasis to the adrenal gland from carcinoma of the stomach and esophagus. Surgery Gynecology and Obstetrics $197714541-48$.

8 Cedermark BJ, Blumenson LE \& Pickren JW. The significance of metastases to the adrenal gland in adenocarcinoma of the colon and rectum. Surgery Gynecology and Obstetrics 1977144 537545.

9 Orth DN, Kovacs WJ \& DeBold CR. The adrenal cortex. In Williams Textbook of Endocrinology, edn 8, pp 489-621. Eds JD Wilson \& DW Foster. Philadelphia: Saunders, 1992.

10 Oelkers W. Current concepts: Adrenal insufficiency. New England Journal of Medicine 1996335 1206-1212. 
11 Shea TC, Spark R, Kane B \& Lange RF. Non-Hodgkin's lymphoma limited to the adrenal gland with adrenal insufficiency. American Journal of Medicine $198578711-714$.

12 Omoigui NA, Cave WT Jr \& Chang AYC. Adrenal insufficiency, a rare initial sign of metastatic colon carcinoma. Journal of Clinical Gastroenterology 19879 470-974.

13 Humnier D, Garty M, Lapidot M, Leiba S, Borohov H \& Rosenfeld JB. Lymphoma presenting with adrenal insufficiency. American Journal of Medicine $1988 \mathbf{8 4} 169-172$.

14 Robertz-Vaupel GM, Glasmacher AG, Vogel J, Vaupel HA, Köster O \& Pizzulli L. Primär beidseitiges, adrenales, hochmalignes B-ZellLymphom mit Meningiosis lymphoblastica. Klinische Wochenschrift 199068 1076-1081.

15 Dobing H, Öhlinger W, Neubauer M, Leb G \& Krejs GJ. Successful treatment of adrenal insufficiency due to malignant nonHodgkin's lymphoma. Clinical Investigations 199270 938-941.

16 Utsunomiya M, Takatera H, Itoh H, Tsujimura T \& Itatani H. Bilateral primary non-Hodgkin's lymphoma of the adrenal glands with adrenal insufficiency: a case report. Acta Urologica Japonica $199238311-314$.

17 Addison T 1865. On the constitutional and local effects of disease of suprarenal capsules. Reprinted in Medical Classics 19372244 280 .

18 Cedermark BJ \& Sjoberg HE. The clinical significance of metastasis to the adrenal glands. Surgery Gynecology and Obstetrics 1981142 607-610.

19 Redman BG, Pazdur R, Zingas AP \& Loredo R. Prospective evaluation of adrenal insufficiency in patients with adrenal metastasis. Cancer $198760103-107$.

20 Van der Pompe G, Antoni MH \& Heijnen CJ. Elevated basal cortisol levels and attenuated ACTH and cortisol responses to a behavioral challenge in women with metastatic breast cancer. Psychoneuroendocrinology $199621361-374$.

21 Chrousos GP. The hypothalamic-pituitary-adrenal axis and immune-mediated inflammation. New England Journal of Medicine $19953321351-1362$.

22 Hussain S, Belldegrun A, Setzer SE, Richie JP, Gittes RF \& Abrams HL. Differentiation of malignant from benign adrenal masses: predictive indices on computed tomography. American Journal of Radiology 1985144 61-65.

23 Francis IR, Smid A, Gross MD, Shapiro B, Naylor B \& Glazer GM. Adrenal masses in oncologic patients: functional and morphologic evaluation. Radiology 1988166 353-356.

24 Oelkers W, Diederich S \& Bähr V. Diagnosis and therapy surveillance in Addison's disease: rapid adrenocorticotropin (ACTH) test and measurement of plasma ACTH, renin activity, and aldosterone. Journal of Clinical Endocrinology and Metabolism 199275 259-264.

25 Reincke M, Nieke J, Krestin GP, Saeger W, Allolio B \& Winkelmann W. Preclinical Cushing's syndrome in adrenal 'incidentalomas': comparison with adrenal Cushing's syndrome. Journal of Clinical Endocrinology and Metabolism 199275 826-832.

26 Silvestri GA, Lenz JE \& Harper SN. The relationship of clinical findings to CT scan evidence of adrenal gland metastases in the staging of bronchogenic carcinoma. Chest 1992102 1748-1751.
27 Salvatierra A, Baamonde C \& Llamas JM. Extrathoracic staging of bronchogenic carcinoma. Chest 199097 1052-1058.

28 Pagani JJ. Non-small cell lung carcinoma adrenal metastases. Cancer 198453 1058-1060.

29 Sheeler LR, Myers JH, Eversman JJ \& Taylor HC. Adrenal insufficiency secondary to carcinoma metastatic to the adrenal gland. Cancer 198352 1312-1316.

30 Seidenwurm DJ, Elmer EB, Kaplan LM, Williams EK, Morris DG \& Hoffman AR. Metastases to the adrenal glands and the development of Addison's disease. Cancer 198454 552-557.

31 Gamelin E, Beldent V, Rousselet M-C, Rieux D, Rohmer V, Ifrah R, Boasson M \& Bigorgne J-C. Non-Hodgkin's lymphoma presenting with primary adrenal insufficiency. Cancer $1992692333-2336$.

32 North RJ, Awwad JM \& Dunn P. The immune response to tumors. Transplantation Proceedings 198921 575-577.

33 Prehn RT. Tumor immunogenity: how far can it be pushed. PNAS $1993904332-4333$.

34 Huang M, Wang J, Lee P, Sharma S, Mao JT, Meissner H, Uyemura K, Modlin R, Wollman J \& Dubinett SM. Human non-small cell lung cancer cells express a type 2 cytokine pattern. Cancer Research 199555 3847-3853.

35 Bernadini R, Kamilaris TC, Calogero AE, Johnson EO, Gomez MI, Gold PW \& Chrousos GP. Interaction between tumor necrosis factor-alpha, hypothalamic $\mathrm{CRH}$, and ACTH secretion in the rat. Endocrinology $19901262876-2881$.

36 Sapolsky R, Rivier C, Yamamoto G, Plotsky P \& Vale W. Interleukin-1 stimulates the secretion of hypothalamic corticotropin-releasing factor. Science 1987238 522-526.

37 Mastorakos G, Chrousos GP \& Weber JS. Recombinant interleukin-6 activates the hypothalamic-pituitary-adrenal axis in humans. Journal of Clinical Endocrinology and Metabolism 199377 1690-1694.

38 Chrousos GP \& Gold PW. The concepts of stress system disorders: Overview of behavioral and physical homeostasis. Journal of the American Medical Association 1992267 1244-1252.

39 Boscaro M, Betterle C, Volpato M, Fallo F, Furmaniak J, Smith BR \& Sonino N. Hormonal response during various phases of autoimmune adrenal failure: No evidence for 21-hydroxylase enzyme activity inhibition in vivo. Journal of Clinical Endocrinology and Metabolism 199681 2801-2804.

40 Findling JW, Waters VO \& Raff $\mathrm{H}$. The dissociation of renin and aldosterone during critical illness. Journal of Clinical Endocrinology and Metabolism 198764 592-595.

41 Reincke M, Lehmann R, Karl M, Magiakou A, Chrousos GP \& Allolio B. In Severe illness: Neuroendocrinology. Annals of the New York Academy of Sciences 1995771 556-569.

42 Raff H \& Findling JW. Aldosterone control in critically ill patients: ACTH, metoclopramide, and atrial natriuretic peptide. Critical Care Medicine 199018 915-920.

Received 23 January 1999

Accepted 13 March 2000 